\title{
Exploration of Academic Postgraduate Medical Training System in the Context of "Internet plus"
}

\author{
Xiaoshan Huang ${ }^{1}$, Longwu Yin ${ }^{1}$, Bilan Zhou ${ }^{1}$, Zhifang Liu ${ }^{1}$, and Meihua Bao,** \\ ${ }^{1}$ Changsha Health Vocational College, Changsha 410604, China \\ ${ }^{2}$ Changsha Medical University, Changsha 410219, China
}

\begin{abstract}
Higher education in China has entered a new era of global quality improvement and innovation. The cultivation of innovative talents is crucial for the development of our higher education. Within the framework of "Internet plus", the culture of university medical graduates must deeply integrate information technology. In the present study, an "Internet plus" academic medical postgraduate training system was discussed. This system includes the establishment of the curriculum system, innovation capability training system and quality evaluation system. By making full use of modern informatics technology, the "Internet plus" system improved the the innovation capability and quality of postgraduates significantly.
\end{abstract}

\section{Introduction}

With the development of our country, "Internet plus" has penetrated into a variety of fields in our life. It promotes technology progress, efficiency improvement, and become an innovation and productivity of our economy [1]. It is important for our higher education to do some reform around "internet plus" in order to adapting the development trend of the society[2]. As an important part of higher education, graduate education is responsible for cultivating knowledge-based and innovative talents. Making use of internet technology and establishing an "Internet plus" talent cultivation mode to enhance the innovation ability of our graduate students has become an important issue in the our higher education system. The present study researched and established an "internet plus" postgraduate education cultivation system to improve the innovation and quality of our postgraduates.

\section{Problems of the current postgraduate education system}

In present, many universities still adopt the "strict entry and lax exit" postgraduate training system, which leads to the lack of innovation of many postgraduates. During the project research, postgraduates usually play the role of project execution and data collection. Many of them are lack of the awareness of positive participation for in the process of project implementation [2,3]. Many of the postgraduates are only satisfied with the completing of their dissertations. In many cases, they lack of the enthusiasm of exploring new knowledge, and lack of the innovation consciousness.

In the process of course teaching for postgraduates, the traditional way of teaching is classroom lectures. However, for postgraduates, the ability of deep exploration in each subjects and the ability of self-learning are particularly important. The current course teaching method can't inspire the independent learning of the students. The traditional "teacher-centered" teaching model also impedes the interests and active thinking of the students and eventually affects the teaching effect [4-6].

A complete evaluation system is a powerful guarantee for the quality of graduate education. However, the present evaluation system for postgraduate teaching quality is mainly focused on the management of the students [7-9]. Construction of the quality evaluation system for postgraduate education basing on the big data under the environment of "Internet plus" is crucial for the improvement of postgraduates education quality and meet the needs of our society.

\section{The construction of "internet plus" postgraduates training system}

In order to serve the local economy better and to arouse the potential of each graduate students, a reform in postgraduate education is inevitable in the era of "Internet plus". Under the background of the "Internet plus", we established a new postgraduates training system. The system includes the establishment of the curriculum system, innovative ability improvement system, and the evaluation system. During the process of postgraduates training, an "Internet plus" platform was built. On the platform, students shared the academic resources without the limitation of time and space. The graduates and supervisors also shared literatures and other materials, provided mutual assistance to each other on the platform [10-12]. We also established the "Internet plus" academic conference and discussion platform. On the platform, remote meetings and discussions were available. Based on the two platforms above, the graduates broadened the academic vision, got access to the most advanced and

* Corresponding author: Meihua Bao@mhbao78@163.com 
cutting-edge knowledge, which is important for improving the innovation of graduate students [13-16]. We also constructed the "Internet plus" courses platform. On the courses platform, graduates are allowed to learn the frontier knowledge of each course systematically, and learn according to their personal conditions and background. The course platform improved their motivation and initiative. The establishment of the "Internet plus" evaluation system helped to give a comprehensive evaluation of the quality of postgraduates. The structure of our "Internet plus" postgraduates training system was shown in Figure 1.
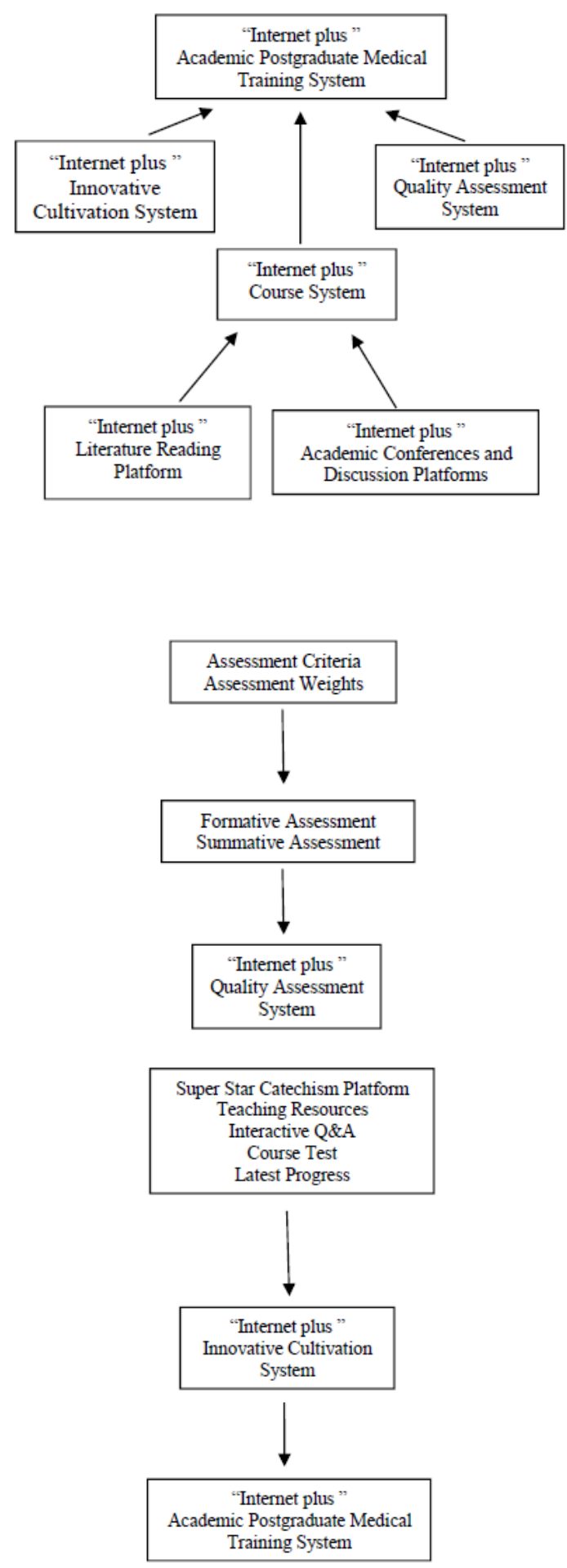

Figure 1 "Internet plus" academic medical postgraduate training system

\subsection{Construction of "Internet plus" postgraduate curriculum system}

To address the problems that postgraduate courses are mainly "teacher centered" lectures, and the students are lack of innovation and inspiration, we established the "Internet plus" courses platform. On the platform, the curriculums were adjusted, the teaching contents were updated, the teaching methods were "students centered", and the managements were strengthened. For example, in the course "Epigenetics", we firstly built an "Internet plus" platform to implement the hybrid teaching of online and offline. Secondly, the teaching content was adjusted. Teachers are required to teach the course gist, latest research progress, and give the exploratory tasks. The students are required to master the main structure and research fields in the course, finish the tasks by reading a large amount of literatures, discuss different topics during class. Thirdly, we reformed the assessment method by using the "Internet plus" platform to ensure the grade point average, peer-assessment, and teacher assessment[17].

To construct the course platform of "Epigenetics", we used the Superstar to establish a course website. Modules such as syllabus, teaching materials, teaching videos, test area and interactive Q\&A area were constructed. The latest progresses and open exploratory questions were presented. A platform operation service team was arranged, and continuously update of the teaching contents was conducted.

\subsection{Construction of system to improve the innovation of postgraduates}

Strengthening the innovation ability of postgraduates is an important way to improve the science and technology competitiveness of our country. It is also one of the core elements in building an innovative country. In order to enhance the innovation ability of postgraduates, we can start from the following aspects:

\subsubsection{Establishment of the "Internet plus" literature reading platform}

Literature reading is a key methods for postgraduates to enhance the knowledge and to grasp the frontiers of each research field. We screened the main literatures in each research field, and uploaded them to the literature reading platform[14]. By analyzing the literature reading data, we got the information of how the postgraduates learned, and involved it to the final assessment of the postgraduates. The platform provided a variety of resource sharing and management services for postgraduates, supervisors and discipline coordinators.

The literature research platform consists of four parts: literature platform establishment, literature screening and uploading, literature reading and management, and literature reading evaluation and assessment. The literature platform can use existing terminals, such as Researcher App or Ketangpai App. The literature screening and uploading can be conducted by the supervisor, using stork software or according to the needs of their fields. The literature reading and management can be managed by the interactive area and testing area of the platform. 


\subsubsection{Establishment of "Internet plus" academic conference and discussion platform}

Academic conferences and academic activities are important tools for the exchange and collision of different academic ideas and the generation of innovative ideas. By combining the regular laboratory meetings with remote video meetings, the potential of mutual learning and cooperation was improved. It also inspired the learning enthusiasm and initiative of the graduates.

For example, we used the "Weiyihui" app to follow and attend the latest academic conferences in our research field. Meanwhile, we establish extensive contact with experts in the field, and organized remote meetings and activities using "Zoom" app.

\subsubsection{Establishment of innovative tutor team}

Under the condition of "Internet plus", a new system of selecting and cultivating tutors is needed. In our new tutor training system, the tutors need to attend training class learning the new multimedia technology, obtaining and sharing the knowledge from the internet platform, improving their own knowledge and teaching skills, guiding graduates to establish the right methods on how to explore the new knowledge. Universities provided sufficient financial support for the training system, maintained a democratic and innovative learning environment, established innovation and venture fund for students. These methods stimulated the enthusiasm of graduate students, helped them focused on scientific research, and strived them for innovation.

Table 1.Impact of Internet Plus on student learning outcomes (points)

\begin{tabular}{|c|c|c|c|}
\hline & $\begin{array}{c}\text { Traditional } \\
\text { Groups }\end{array}$ & $\begin{array}{c}\text { Internet Plus } \\
\text { Group }\end{array}$ & $\mathrm{P}$ \\
\hline Age (years) & $21.3 \pm 3.3$ & $20.8 \pm 2.5$ & $>0.05$ \\
\hline $\begin{array}{c}\text { Comprehensi } \\
\text { ve evaluation }\end{array}$ & $74.2 \pm 3.2$ & $72.9 \pm 3.5$ & $>0.05$ \\
\hline Exam Results & $72.6 \pm 3.5$ & $81.5 \pm 2.8$ & $<0.05$ \\
\hline $\begin{array}{c}\text { Learning } \\
\text { Motivation }\end{array}$ & $81.2 \pm 3.3$ & $89.8 \pm 3.8$ & $<0.05$ \\
\hline $\begin{array}{c}\text { Learning } \\
\text { Attitude }\end{array}$ & $53.5 \pm 2.7$ & $64.1 \pm 4.5$ & $<0.05$ \\
\hline
\end{tabular}

\section{Establishment of "Internet plus" quality evaluation system}

A comprehensive and quality evaluation system is a powerful guarantee for the cultivation of postgraduate students. It is of great practical significance to improve the quality of postgraduate education by building a quality evaluation system based on "Internet plus".

The new evaluation index system starts from the system construction, exploring the construction of postgraduate assessment and evaluation system including supervision mechanism, feedback mechanism, incentive mechanism, elimination mechanism, etc, guaranteeing the implementation of the evaluation system to achieve effective results,

We established an evaluation system that covers the whole process of postgraduate education. This evaluation system combined formative and summative evaluation. The students' basic quality, scientific research ability, employment and social evaluation were involved in this system. The "Yaahp" software was used to analyze the weight of each index and to construct a reasonable quality evaluation system of postgraduates. This system included supervision, feedback, incentive and elimination processes, and form a virtuous cycle of "evaluation-feedback-incentive-improvement". All the connotations were clarified, and the valuation criteria were quantified.

\section{Conclusion}

The high education in our country has entered a new era of comprehensive quality improvement and innovation. The high education is a strategic tool, a key driving force, a major contributor, and an important source of policy in the development of our country. Postgraduate medical education is an important part of Chinese universities. Further improve the quality of practice teaching in medical schools. Further improve the quality of practice teaching in medical schools. It is still necessary for the majority of medical educators to pool their wisdom and come up with strategies.

As long as the attitude of seriousness and responsibility, insisting on seeking truth from facts the law of practical teaching, with the help of the "Internet plus education"east wind", We believe that in the near future, we will be able to innovate more perfect teaching methods.

It is still in the exploration stage of how to use the Internet resources to continuously improve the quality of students' practical teaching.The cultivation of graduates with high level of innovation and quality is essential. Under the background of "Internet plus", the integration of modern information technology with the cultivation of postgraduates improves the innovation ability and quality of postgraduates.

\section{Acknowledgments}

The present research is supported by the Foundation of Hunan Provincial Degree and Postgraduate Education Reform (Grant No. 2019JGYB286) and the Scientific Research Project of Hunan Provincial Education Department(Grant No. 20C0142) .

\section{References}

1. D.Q. Zheng, Y.J. Fan, R. Pan, H.M. Cai. Exploring the concept and elements of big data governance [J]. Science and Technology Management Research. 37(15): 200-205(2017)

2. C.J. Liang, S.S. Bi. Reflections on the Research of Graduate Student Training Model[J]. Research on graduate education. (01): 11-15+62(2015)

3. Q. Liu, Y. Yang. A comparison of the advantages and disadvantages of traditional and innovative 
medical postgraduate training models $[\mathrm{J}]$. Guangxi Medicine. 41(10): 1336-1337(2019)

4. Liu J, J.M. Liu. Survey and research on the current situation of postgraduate course teaching optimization and reform from the perspective of quality culture [J]. Journal of Mudanjiang College of Education. (07): 39-41+44(2018)

5. H.G. Guo, F. Wang, Z.G. Li. Teaching reform and practice of postgraduate courses based on "Internet + " [J]. Journal of Shanxi College of Economics and Management Cadres. 26(03): 9295(2018)

6. S.G. Du, X.D. Wang. Exploring the change of classroom teaching structure in the era of "Internet+" [J]. Educational exploration. (02): 2832(2017)

7. L. Liu, D.G. Wu, Y. Chen, S.M. Liu. Exploration of the quality evaluation system for the training of master's degree students in clinical medicine[J]. Chinese Continuing Medical Education.10(33): 6365(2018)

8. Y.Yang, W. Wang. Exploration and practice of building a quality evaluation system for postgraduate course teaching [J]. Curriculum Education Research. (17): 228(2019)

9. C.J. Huang,J.L. Gao,Jia.S. Ren. Problems and countermeasures in postgraduate training of clinical medicine degree[J]. China Higher Medical Education,(07):115-116(2014)

10. S.Ying,J. Kang, L.Zhen, X.M.Ding. Exploration and practice of postgraduate training model reform in China[J]. Graduate Education Research,(01):15(2014)

11. Q. Li,Y.X. Zhao,P. Xu ,W.J. Chen .Wu Yixian,Dong Juanjuan,Feng Shumei. Exploring the reform strategy of medical postgraduate practice teaching based on "Internet+"[J]. Basic Medicine and Clinical,39(08):1205-1208(2019)

12. H.T.Yu, Exploring the five-step method of intelligent teaching in colleges and universities based on rain classroom--Taking the course of "Network Education Application" as an example[J]. Modern Educational Technology,28(09):5458(2018).

13. X.M. Wen,D.H. Hu,W.B. Wang,D.Liu . Exploration and practice of reforming postgraduate training mode in the Internet era--Beijing University of Posts and Telecommunications as an example[J]. Industrial and Information Technology Education,(08):75-79(2017)

14. X. Zhang,J.Ch. Jiang ,J.M.Gong . Exploration and practice of the reform of applied postgraduate training mode $[\mathrm{J}]$. China Electricity Education,(07):13-15(2013)

15. H.M. Bo,J.M. Li, X.P. Zhang. The construction of teaching quality assurance system for graduate students of clinical medicine based on the training of excellent doctors [J]. China Health Career Management. 32(4): 294, 309(2015)

16. F.R. Xu, Z.F. Jiang. Discussion on the cultivation model of clinical medicine graduate students [J]. China Higher Medical Education. (1):129-130(2017)

17. H.T. Han, S. Hou, X.G. Zheng. Exploring the reform and construction of postgraduate course teaching in the new era [J]. Degree and Graduate Education.(1): 25-29(2016) 